\title{
THE INTRODUCTION OF PROGRAM BUDGETING IN RUSSIA: 20 YEARS OF EXPERIENCE WITH RUSSIAN BUDGETARY REFORMS*
}

\section{Afanasiev Mstislav P.}

Doctor of Economics; Head of Public Finance Department, HSE. Address: National Research University Higher School of Economics. 20, Myasnitskaya St., Moscow 101000, Russian Federation.

E-mail: mstafan@hse.ru.

\section{Shash Natalia $\mathbf{N}$.}

Doctor of Economics; Professor, Public Finance Department, HSE. Address: National Research University Higher School of Economics. 20, Myasnitskaya St., Moscow 101000, Russian Federation.

E-mail:nat_vshu@mail.ru.

\begin{abstract}
This paper examines Russia's 20 years of experience with budgetary reforms. The authors focus most of their attention on the introduction into Russian budgetary practice of special-program methods, which is a key feature of the ongoing budgetary reform in the country. The main phases of the reform of the budgetary process are analyzed, from the formulation of programs for socio-economic development and the first attempts to apply the tools of program budgeting (the formulation of special federal programs) to the preparation of the federal budget on the basis of government programs and the transition to a program-based budgetary format for constituent entities of the Russian Federation.
\end{abstract}

Keywords: budgetary reforms; special-program methods; special federal programs; special government-agency programs; results-based budgeting; evaluating program effectiveness

$\mathrm{T}$ he purpose of the article is to analyze the key results of current budgetary reforms; to diagnose and identify the strategic problems impeding the process of introducing special-program methods into Russian budgetary practice; and to propose a set of practical measures to streamline the administration of government programs.

The paper accomplishes the following tasks:

- $\quad$ assesses the phases of the introduction of special-program methods into the budgetary process of the Russian Federation (RF) in terms of successes and failures;

* Translated by Steven Shabad. 
- identifies the major flaws in government programs stemming from the unsatisfactory quality of their formulation, including the absence of a direct link between the objectives, actions, and performance indicators of government programs, and by the choice of tools for evaluating them;

- defines the key elements of effectiveness and proposes criteria of effectiveness that should be applied when evaluating the results of the implementation of government programs;

- examines the specific features of various groups of indicators in the case of concrete government programs, proposes model indicators, and formulates an algorithm for evaluating the effectiveness of environmentally oriented government programs;

- identifies key problems that arise in the process of formulating and implementing the government programs of constituent entities in the RF and the factors preventing their transformation into an effective tool for achieving the strategic objectives of the country's development;

- formulates practical recommendations aimed at making government programs more effective at the federal and regional levels, including recommendations for increasing the transparency of budgetary procedures.

The massive scale of the budgetary reforms makes it difficult to describe in detail all of the actions that have been taken to modernize public finance. Therefore, this paper will focus on the introduction of special-program methods into budgetary practice, which the authors believe is the key aspect of the ongoing budgetary reform in Russia.

\section{The prerequisites for the transition to program budgeting}

The starting point for the transition to program budgeting was the entry into force of Federal Law No. 115-FZ of July 20, 1995, "On Government Forecasting and Programs for the Socio-Economic Development of the Russian Federation," which defined the objectives and content, as well as the general procedure, for drawing up forecasts and programs for the socio-economic development of the RF. This law subsequently became the foundation for creating a legal framework in this area.

Socio-economic programs for the medium term (Afanasiev \& Shash, 2014, p. 56) began during this period to be based on data from the long-term forecast and strategy for socio-economic development. These documents were used as a guide in drawing up regional socio-economic programs, which were supposed to become tools for a comprehensive analysis of the situation in the constituent entity of the federation and for formalizing the priorities of socio-economic development and the planning of key activities to be funded by budgets at all levels in the medium term. Thus, the use of comprehensive programs of regional development in present-day Russia developed steadily; in 2008 the number of regional programs in effect in the country reached 50 (the most since the reforms began).

These regional programs were expected, on the one hand, to be organically built into the documents that defined the priorities for the development of the country as a whole, and on the other, to make it possible to coordinate sectoral 
priorities within the region. During this period the transition to special-program methods of administration allowed planned budget expenditures to be linked to the priority areas of the country's policies by shifting the focus from managing costs to attaining important socio-economic objectives.

The next phase in Russia's budgetary reforms - in the late 1990s and the 2000s - was the implementation of a whole host of special federal programs (SFPs), for which the regulatory framework derived from Resolution No. 594 of June 26, 1995, of the Russian Federation Government, "On Implementation of the Federal Law 'On Deliveries of Goods for Federal Government Needs,' " and Resolution No. 842 of December 25, 2004, "On Revisions to the Procedure for Formulating and Implementing Special Federal Programs and Intergovernmental Special Programs to Which the Russian Federation is a Party."

These programs became one of the most important means of pursuing the Russian state's structural policy and of actively influencing socio-economic development, since they were focused on implementing the most important, large-sale investment and scientific-technical projects for the country that are aimed at solving systemic problems that fall within the jurisdiction of federal authorities.

The guidelines for implementing SFPs provided for an open tendering procedure for allocating funds, experts' assessments of the results of project implementation, a clear-cut definition of areas of activity, and earmarking of government investments, which was supposed to promote the development of competition among the recipients of budget funds for additional funding sources and more efficient utilization of budget funds. The structure and phases of the formulation of SFPs are shown in Figures 1 and 2.

\section{Structure of a special federal program (SFP)}

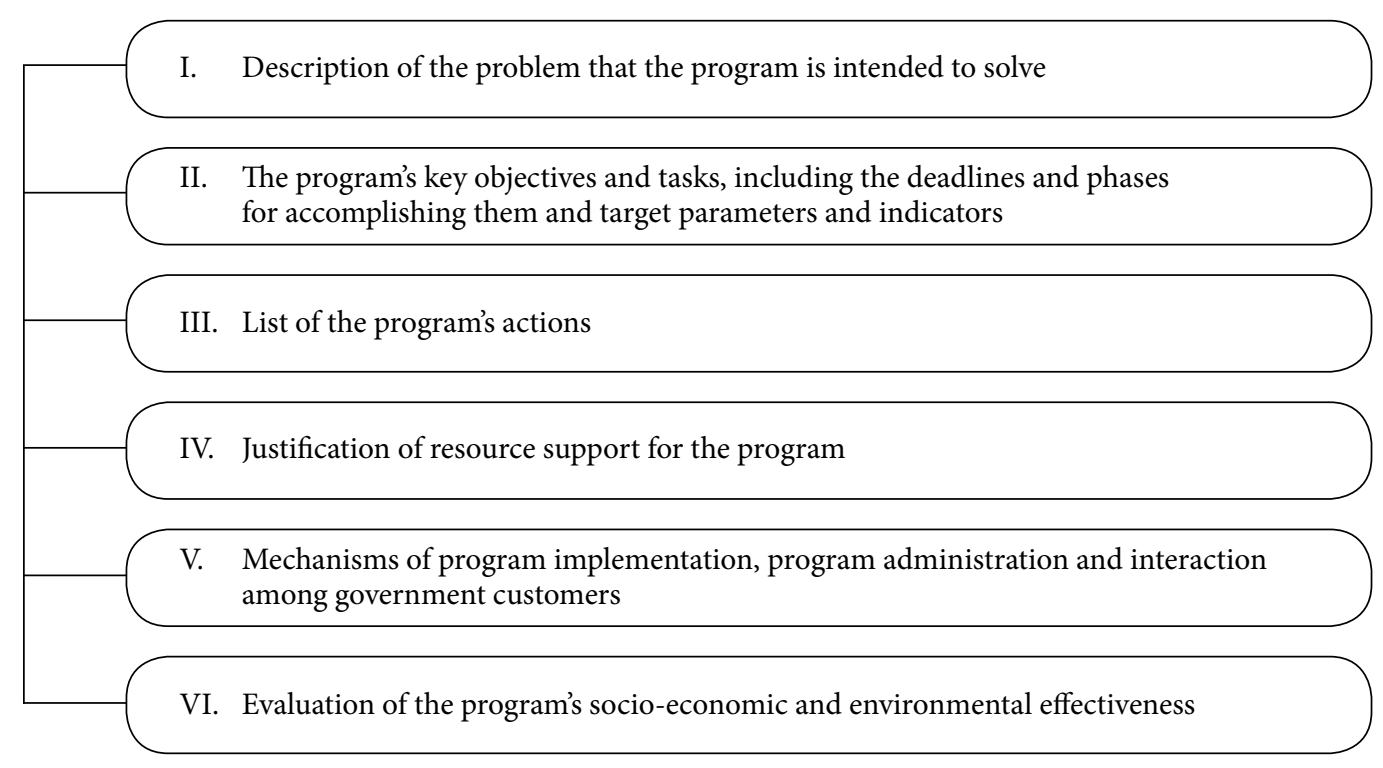

Source: Afanasiev, Shash, \& Belenchuk, 2012, p. 157. 
Figure 2

\section{Phases of formulation and implementation of a special federal program}

\begin{tabular}{|l|l|}
\hline PHASE 1 & Choice of a problem for program formulation \\
\hline \multicolumn{2}{|l|}{} \\
\hline PHASE 2 & Decision-making to draw up a program and its formulation \\
\hline & \\
\hline PHASE 3 & Expert review and evaluation of programs \\
\hline & \\
\hline PHASE 4 & Program approval \\
\hline & \\
\hline
\end{tabular}

Source: Afanasiev, Shash, \& Belenchuk, 2012, p. 160.

However, an analysis of the experience of introducing SFPs in the Russian Federation in the early 2000s suggests that they have not become truly effective and have been transformed from a tool for consolidating resources in priority development areas into a means of justifying additional funding for the current activities of government authorities (Afanasiev, Shash, \& Belenchuk, 2012, p. 161).

It should be stressed that the ineffectiveness of SFPs stemmed mainly from the unsatisfactory work of government customers at every phase of the life cycle of these programs, that is, during their formulation, implementation, and working-out of oversight mechanisms. Nevertheless, at that time special federal programs were the most transparent and refined tool for implementing public policy by using special-program methods.

\section{Medium-term budget planning and results-based budgeting}

The need for modernizing special federal programs in the mid-2000s in order to make them more effective and productive was dictated both by the tasks of achieving a high rate of economic growth and by the restructuring of the system of government that was in progress during that period. As a result, the Russian Federation Government adopted Resolution No. 249 of May 
22, 2004, "On Measures to Increase the Productivity of Budget Expenditures," whose implementation included approval of the Framework for Reforming the Budget Process in the Russian Federation in 2004-2006 in the areas shown in Figure 3.

Figure 3

\section{Key areas of the framework for reforming the budget process in the Russian Federation in 2004-2006}

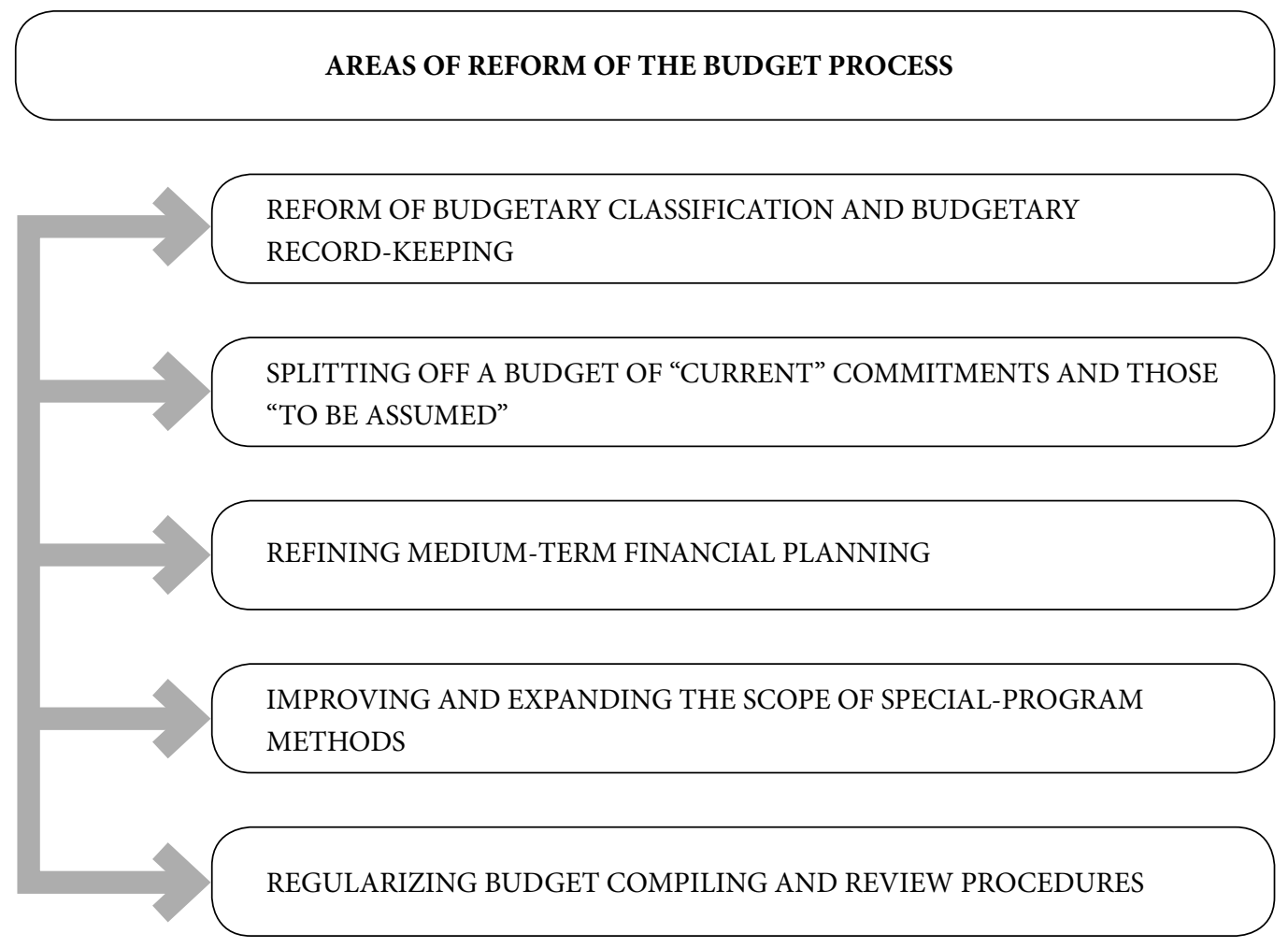

Source: Produced by the authors on the basis of the provisions of Russian Federation Government Resolution No. 249 of May 22, 2004.

This became the foundation for building a legislative framework for a transition to medium-term financial planning and results-based budgeting (RBB) (Afanasiev \& Krivogov, 2006, p. 36).

The transition to multiyear budget planning, which marked the beginning of the next phase of the budgetary reform, created new opportunities for increasing the effectiveness of program methods. The annual cycle of budget plans was coming into conflict with the ideology and practice of using program tools, which made it necessary to expand the horizon of budget planning. In addition, the introduction of RBB required the establishment of clear-cut rules for modifying the amount and structure of budget appropriations during a regular budget cycle, which made the Russian budget more predictable and hence more stable. 
The effectiveness of new reporting requirements, however, did not meet expectations, and as a result, as part of the implementation of the Framework for Reforming the Budget Process, the Russian Federation Government adopted Resolution No. 239 of April 19, 2005, "On Approval of the Statute on the Formulation, Approval and Implementation of Special Government-Agency Programs."

A special government-agency program (SGAP) contained a set of interconnected actions aimed at accomplishing a concrete tactical task described by measurable indicators - quantitative characteristics for each year of its implementation. In addition, these budget programs were to include indicators for determining the degree of attainment of planned results and objectives, as well as the planned level of budget appropriations.

An analysis of the use of SGAPs as a tool of budget planning in all of the constituent entities and in more than thirty of Russia's municipalities identified problems in a number of important areas (Fig. 4).

\section{Key problem areas in the implementation of special government-agency programs (SGAPs)}

Figure 4

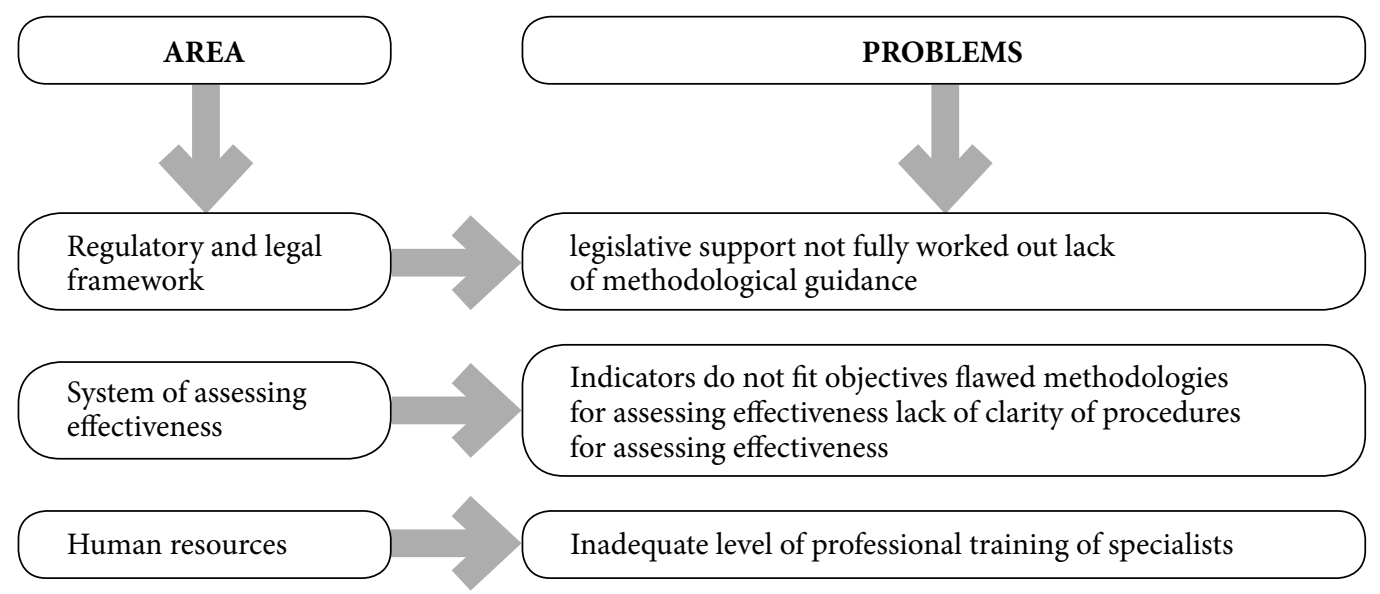

In addition, the analysis showed that the ineffectiveness of SGAPs derived in large part from the fact that regions directly duplicated the federal experience without taking into account the characteristics of their specific regions and without linking them more precisely with their own powers, spending commitments, and project funding (Afanasiev \& Shash, 2014, p. 51). For example, when many Russian constituent entities worked out a methodological framework, they took RF Government Resolution No. 239 of April 19, 2005, as a basis, which reproduced defects and outright errors that were made at the federal level. Moreover, despite the fact that this type of program was created in order to regularize the budget's current spending commitments, in practice the authors of governmentagency programs often used them as a means of arguing for obtaining additional budget funds. 
None of these setbacks, however, led to an abandonment of introducing special-program administrative methods into the budget process, the next phase of which was the appearance of government programs.

\section{The formulation and implementation of government programs}

The formulation of new budget programs was launched in August 2010 with issuance of the Russian Federation Resolution (No. 588) "On Approval of the Procedure for Formulating, Implementing, and Evaluating Government Programs of the Russian Federation."

The formulation of government programs may be regarded as an attempt to consolidate all previously used tools for achieving the objectives of public policy. Russia at present has a whole host of high-level government tasks that can be accomplished only with the participation of several ministries. Such tasks cover integrated currents in public policy that are pursued specifically in the form of RF government programs, whose principal indicators must be reflected in a medium-term forecast for the country's socio-economic development.

Beginning in 2011, the rendering of the expenditure portion of the federal budget in program format became one of the main tasks of the RF Government Program to increase the effectiveness of budget expenditures for the period up to 2012 (approved by Directive No. 1101-r of June 30, 2010). As a result, the expenditure portion of the budgets of all subsequent periods - 2011-2013, 2012-2014, 2013-2015, and 2014-2016 (along with the traditional one) - was partially presented in program format (Table 1 ).

Table 1

\section{Program expenditures and nonprogram expenditures in the RF budget, 2011-2016 (billions of rubles, \%)}

\begin{tabular}{|l|c|c|c|c|c|c|c|c|}
\hline \multirow{2}{*}{$\begin{array}{c}\text { RF federal } \\
\text { budget } \\
\text { expenditures }\end{array}$} & \multicolumn{2}{|c|}{$\mathbf{2 0 1 1 - 2 0 1 3}$} & \multicolumn{2}{c|}{$\mathbf{2 0 1 2 - 2 0 1 4}$} & \multicolumn{2}{c|}{ 2013-2015 } & \multicolumn{2}{c|}{ 2014-2016 } \\
\cline { 2 - 9 } & bln rubles & in \% & bln rubles & in \% & bln rubles & in \% & bln rubles & in \% \\
\hline $\begin{array}{l}\text { program } \\
\text { expenditures }\end{array}$ & $27,392.2$ & 80.4 & $38,447.2$ & 93.8 & $20,753.1$ & 48.1 & $25,161.7$ & 56.5 \\
\hline $\begin{array}{l}\text { nonprogram } \\
\text { expenditures }\end{array}$ & $6,679.9$ & 19.6 & $2,522.7$ & 6.2 & $22,467.5$ & 51.9 & $19,348.0$ & 43.5 \\
\hline Totals & $34,072.1$ & & $40,969.9$ & & $43,220.6$ & & $44,510.2$ & \\
\hline
\end{tabular}

Source: Official website of the Ministry of Finance of the Russian Federation (ww.minfin.ru).

The program portion of the Russian federal budget over the past four budget cycles has been presented in the form of the totality of government programs, grouped into five main blocks. In addition, the number of programs being implemented and the amounts of their funding have been updated in each subsequent budget cycle (Table 2). 
Table 2

\section{Allocation of budget funds by key blocks of government programs, 2011-2016}

\begin{tabular}{|l|c|c|c|c|c|c|c|c|}
\hline \multirow{2}{*}{ Program block } & \multicolumn{3}{|c|}{$\begin{array}{c}\text { Number of government } \\
\text { programs by blocks }\end{array}$} & \multicolumn{4}{c|}{ Funding, billions of rubles } \\
\cline { 2 - 9 } & $\begin{array}{c}\mathbf{2 0 1 1 -} \\
\mathbf{2 0 1 3}\end{array}$ & $\begin{array}{r}\mathbf{2 0 1 2 -} \\
\mathbf{2 0 1 4}\end{array}$ & $\begin{array}{c}\mathbf{2 0 1 3 -} \\
\mathbf{2 0 1 5}\end{array}$ & $\begin{array}{c}\mathbf{2 0 1 4} \\
\mathbf{2 0 1 6}\end{array}$ & $\begin{array}{c}\mathbf{2 0 1 1 -} \\
\mathbf{2 0 1 3}\end{array}$ & $\begin{array}{c}\mathbf{2 0 1 2} \\
\mathbf{2 0 1 4}\end{array}$ & $\begin{array}{c}\mathbf{2 0 1 3} \\
\mathbf{2 0 1 5}\end{array}$ & $\begin{array}{c}\mathbf{2 0 1 4} \\
\mathbf{2 0 1 6}\end{array}$ \\
\hline $\begin{array}{l}\text { Innovative } \\
\text { development } \\
\text { and modernization } \\
\text { of the economy }\end{array}$ & 17 & 17 & 17 & 17 & $4,710.7$ & $5,982.7$ & $5,594.3$ & $6,210.7$ \\
\hline New quality of life & 11 & 13 & 12 & 12 & $14,495.5$ & $18,500.8$ & $9,749.3$ & $10,279.0$ \\
\hline $\begin{array}{l}\text { Efficient } \\
\text { government }\end{array}$ & 5 & 5 & 5 & 4 & $4,890.3$ & $4,412.7$ & $3,378.5$ & $3,549.2$ \\
\hline $\begin{array}{l}\text { Balanced regional } \\
\text { development }\end{array}$ & 4 & 4 & 5 & 5 & 782.5 & $1,890.3$ & $2,008.7$ & $2,262.6$ \\
\hline $\begin{array}{l}\text { Safeguarding } \\
\text { national security }\end{array}$ & 2 & 2 & 1 & 1 & $2,513.2$ & $7,660.8$ & 22.4 & 5.3 \\
\hline $\begin{array}{l}\text { Expenditures } \\
\text { on activities } \\
\text { in RF government } \\
\text { programs that } \\
\text { are state secrets }\end{array}$ & & & & & & & & \\
\hline \begin{tabular}{l} 
TOTALS: \\
\hline
\end{tabular} & 39 & 41 & 40 & 39 & $27,392.2$ & $38,447.2$ & $20,753.1$ & $25,162.2$ \\
\hline
\end{tabular}

Source: Official website of the Ministry of Finance of the Russian Federation (ww.minfin.ru).

As Table 1 shows, the program portion of federal budget expenditures began to decline in 2013, a result of the decrease in the number of government programs. These were programs with a large amount of funding, including the program to develop the pension system. This increased the share of nonprogram expenditures, since budget appropriations for the development of the pension system were planned in the amount of 9,320.1 billion rubles. In late April 2013 the State Duma adopted amendments to the Budget Code (No. 104-FZ of May 7, 2013) that were needed for the transition to a full-fledged program budget. These legislative revisions were expected to serve as an incentive for the Russian federal budget in the next budget cycle, 2014-2016, to be produced entirely in program format. But this did not happen. And as Table 1 shows, the share of program expenditures in the federal budget in 2014-2016 was 56.5 percent (an increase of only 8.4 percentage points over the previous budget). The reason for this was that two government programs that were intended to support national defense and develop the pension system and that provided for a large amount of funding were not adopted in 2014. Thus, 8,141.7 billion rubles were to be allocated for development of the pension system and 8,925.3 billion rubles for secret expenditures, including financial support for national defense. In the end, these expenditures remained in the "nonprogram" portion of budget expenditures. 
In addition, inattention to the Russian economy's structural problems at a time of deteriorating international conditions and economic sanctions that were imposed became a serious obstacle to a transition to a full-fledged program budget. The unfavorable macroeconomic situation and the lack of incentives for development of the real sector of the economy have resulted in a recession and have limited internal opportunities for economic growth. All of this has adversely impacted financial support for government programs due to the need for substantial budget adjustments, since the draft federal budget for 2014-2016 was prepared at a time when previously forecast revenues were declining.

It is no accident that the idea of cutting government spending was the main thrust of the President's Budget Message of 2013. Sequestration affected most areas of budget expenditures. Worst hit was the housing and utilities sector, on which spending was to be reduced by roughly one-quarter (37 billion rubles). Spending on education was cut by 13 percent (or 88 billion rubles). In addition, a draft was prepared for optimizing government expenditures that would cut them by 1.1 trillion rubles, including by changing the procedure for funding the pension system and restructuring the public administration sector. Naturally, all of this, along with the worsening forecasts for the revenue portion of the budget, could not help but impact the amounts of funding and the allocation of budget resources for government programs in progress. Underfunding, however, is not the main reason for their ineffectiveness; a number of complex problems remain, and vigorous measures must be taken to solve them.

\section{What is an effective government program?}

The government programs being implemented in Russia have substantial differences from the majority of public programs being implemented in the United States, Canada, France, Sweden, South Korea, and other countries. Essentially they are more in line with the "missions" in France and "interagency programs" in South Korea. Each government program in the Russian Federation has its own structure and may include:

- $\quad$ subprograms and/or special federal programs;

- $\quad$ special government-agency programs and/or principal measures;

- measures.

Therefore government programs contain significant variations, based not only on the scale of the tasks to be accomplished but also on structural elements.

The multifaceted nature of government programs requires that even during the phase of the formulation of the federal budget, they must meet certain conditions, which may be regarded as the key elements of the effectiveness of government programs:

- clear formulation of the program objective;

- development of a logical structure for the program;

- a sound system for evaluating program effectiveness.

To be fair, it should be noted that this list is by no means complete. For example, there are a number of other requirements (including the definition of program subobjectives for each participating ministry; the allocation of responsibility 
for the results of program fulfillment among participating ministries; the design of an incentive system for achieving targets) that are no less important. The latter, however, are not crucial, since without the first three, it is altogether impossible to talk about the effectiveness and productivity of budget expenditures (which is what special-program budgeting is actually aimed at).

The application of special-program budgeting methods in Russia is continuously developing, moving toward a modernization of the regulatory and legal framework. In December 2013 the Russian Federation Ministry of Economic Development issued an order approving the new version of the guidelines for the formulation and implementation of government programs. The new guidelines contain a list of requirements for objectives, which must conform to the priorities of public policy for the implementation of government programs and define the end results of their implementation. Furthermore, the objectives of a government program must possess such characteristics as specificity (the objective must be consistent with the domain in which the government program is implemented); concreteness (no fuzzy, obscure formulations that allow for an arbitrary or ambiguous interpretation); measurability (the attainment of the objective can be verified); achievability (the objective must be achievable during the period of implementation of the government program); relevance (conformity of the formulation of the objective with the expected end results of the implementation of the program). In addition, the formulation of the objective must be concise and clear and not contain special terms, references to other objectives, tasks, or results that are corollaries of achieving the objective itself, or a description of ways, means and methods of achieving it.

Our analysis, however, suggests that in most cases government programs need to be further refined, for example, with regard to formulating objectives. We can cite, in particular, government program 05, "Providing High-Quality and Affordable Housing and Services for RF Citizens," in which neither of the objectives - "Improving the affordability and quality of housing for the public" and "Improving the quality and reliability of the provision of housing and utility services" - meets the requirements of current guidelines. All of this also applies to other government programs, since it is impossible to regard as concrete, achievable, realistic, and measurable such objectives as: "Making health care accessible and improving the effectiveness of health-care services, the amount, types, and quality of which must be in line with the morbidity level, the public's needs, and advanced medical achievements" (government program 01, "The Development of Health Care") and "Creating legal, economic, and institutional conditions conducive to the effective development of the labor market" (government program 07, "Support for Employment of the Population").

It must be acknowledged that there are serious problems with the logical structures of programs, most of which lack sections containing information about their interconnection with related government programs. In addition, disagreements over the approval of ceilings of budget appropriations for their implementation led to a point where a "compromise" solution was worked out in 2013 that provided for the possibility of formulating all government programs in two versions or scenarios: a baseline one (within the framework of the adopted three-year 
budget) and a supplemental (preferred) one, which would provide for additional budget appropriations with an appropriate modification of targets. The result was that the majority of approved government programs in 2013 were approved in two scenarios (baseline and supplemental). Moreover, the approved programs were formulated in different formats, since substantial changes had occurred during this period in the regulatory and legal framework. This resulted in the fact that in the middle of 2014, all current government programs underwent a substantial reworking. The new versions of the government programs, however, are also far from being perfect (http://programs.gov.ru).

It must be noted that if the first two elements of the government programs do not meet the requirements, it is pointless to speak of a system for evaluating their effectiveness, since it is impossible to evaluate a program's effectiveness without a clear understanding of exactly what results must be achieved.

Moreover, one of the basic conditions for government programs to be effective is that there should be a direct relationship between actions and the parameters of the evaluation. If we try to trace that relationship, a whole host of questions arise. Take, for example, the government program "The Development of Education for 2013-2020," whose objectives are:

- to provide a high quality in Russian education based on the changing needs of the population and the long-term challenges of the development of Russian society and the economy;

- making youth policy more effective for purposes of the country's innovative social development.

The proposed indicators (there are seven in all) include those presented in Table 3.

Table 3

\section{Indicators of the government program for the development of education}

\begin{tabular}{|l|c|c|c|c|c|}
\hline \multicolumn{1}{|c|}{ Indicators } & $\mathbf{2 0 1 3}$ & $\mathbf{2 0 1 4}$ & $\mathbf{2 0 1 5}$ & $\mathbf{2 0 1 6}$ & $\mathbf{2 0 2 0}$ \\
\hline $\begin{array}{l}\text { Percentage of the total population 5-18 years of age } \\
\text { covered by education }\end{array}$ & 98.5 & 98.3 & 98.0 & 98.0 & 98.0 \\
\hline $\begin{array}{l}\text { Percentage of young people 14 to 30 years of age who } \\
\text { participate in the activities of public young people's } \\
\text { associations }\end{array}$ & 21.0 & 22.0 & 23.0 & 23.0 & 23.0 \\
\hline $\begin{array}{l}\text { Percentage of children in families with incomes below } \\
\text { the poverty level }\end{array}$ & 26.4 & 26.0 & 25.8 & 24.2 & 20.9 \\
\hline Total fertility rate & 1.643 & 1.664 & 1.685 & 1.711 & 1.815 \\
\hline
\end{tabular}

Source: Created by the authors.

It is not very clear how one can tie these indicators to the declared objectives - specifically, how it is possible, by means of a reduction (even a small one) in the percentage of young people receiving an education and an increase in the number of young people taking part in public activities, to provide a high quality of education and at the same time promote innovative and socially oriented devel- 
opment of the country. It seems that this program needs to be seriously revamped with regard to developing a system for evaluating effectiveness.

Obviously, an indicator such as total fertility rate is not related in any way to the stated objectives of the government program, and therefore the effectiveness of budget expenditures on this program comes under question.

There are no fewer contradictions in the objectives and indicators of the government program "Economic Development and an Innovative Economy." The first thing to point out is the effectiveness of the objectives. It is not very clear why one of three stated declared objectives is "to make public administration more efficient" (the other two are: to create a favorable entrepreneurial climate and conditions for doing business and to increase the innovative activities of business) and to which objective, for example, the indicator "level of accessibility of official statistical information" corresponds.

These examples clearly demonstrate that a number of objectives are not effective, and as is well known, objectives that are not precisely formulated often may "lead in the wrong direction." You can be effective, carry out all of the stated activities, but move in the wrong direction.

\section{Constructing a system for evaluating the effectiveness of government programs}

The question of which parameters to include in a system for evaluating effectiveness is essentially a matter of receiving feedback for the improvement of government programs. Besides audit functions, an important aspect that should be kept in mind is whether the parameter/indicator provides information about what is happening e.g., quality, cost, etc.). Information on the changes that are taking place are provided specifically by parameters of effectiveness that represent the relationship between the degree to which the planned results have been achieved and the use of a certain amount of budget funds. Another problem is the fact that the proposed methodologies of government programs do not provide an evaluation of parameter levels with reference to funding amounts from each funding source (in addition to the variety of options for calculating parameters of effectiveness and of methods of obtaining reporting data).

The specific nature of the objectives, tasks, activities, and results of some government programs is such that the benefits from their implementation are indirect, circuitous, and pertain not only to the development of the sectors in which such programs are implemented but also to the living standards and quality of life, the social sector, the economy, public safety, government institutions, and so forth. All this makes it impossible to adequately evaluate the effectiveness of government programs. In addition, when evaluating a whole host of Russian government programs, one must pay special attention to calculating parameters not only of economic but also of social effectiveness. If we look at Russian practice, we will see that this is especially applicable to socially oriented programs in the "New Quality of Life" block, such as "Support for Employment of the Population," "The Development of Health Care," "The Development of Education," "The Development of the Pension System," and others. 
We will now examine the specific nature of various groups of parameters in the case of the implementation of the subprograms included in the government program "Environmental Protection" for 2012-2020 (the "New Quality of Life" block) with 2014 funding of 31.7 billion rubles, the purpose of which is to raise the level of environmental safety and to preserve natural systems.

When formulating and implementing environmental subprograms ("Regulating the Quality of the Environment," "Russia's Biological Diversity," "Hydrometeorology and Environmental Monitoring"), it is important to orient expenditures toward achieving specific objectives and to evaluate their effectiveness on the basis of measurable indicators. One should therefore take into account a whole set of parameters that allow for evaluating not only environmental and social but also economic effectiveness (Afanasiev \& Shash, 2013, p. 61).

Examples of parameters for environmental programs are shown in Table 4.

Table 4

\section{Examples of parameters for evaluating the effectiveness of environmental programs}

\begin{tabular}{|c|c|}
\hline \multicolumn{2}{|c|}{ Parameters of effectiveness of environmental programs } \\
\hline \multirow{6}{*}{$\begin{array}{l}\text { Parameters } \\
\text { of environmental } \\
\text { benefits }\end{array}$} & Share of solid-waste generation per capita* \\
\hline & $\%$ of production-waste generation \\
\hline & $\%$ of production waste recycled \\
\hline & $\%$ of consumption-waste generation \\
\hline & $\%$ of consumption waste recycled \\
\hline & $\%$ of enterprises that improved their level of hazardous emissions \\
\hline \multirow{3}{*}{$\begin{array}{l}\text { Parameters } \\
\text { of social } \\
\text { benefits }\end{array}$} & $\%$ of morbidity rate caused by environmental situation \\
\hline & $\%$ of mortality rate caused by environmental situation \\
\hline & Social benefit from environmental investments \\
\hline \multirow{7}{*}{$\begin{array}{l}\text { Parameters } \\
\text { of economic } \\
\text { benefits }\end{array}$} & Resource-intensiveness of the economy \\
\hline & Energy-intensiveness of production \\
\hline & Proportion of environmentally clean output \\
\hline & Economic benefits from environmental investments \\
\hline & Increase in value of lands after environmental-protection measures \\
\hline & Increase amount of fines for violation of environmental rules \\
\hline & $\begin{array}{l}\text { Amount of annual economic harm from deterioration in condition of the } \\
\text { environment }\end{array}$ \\
\hline
\end{tabular}

Source: Created by the authors.

${ }^{\star}$ It is important to include this parameter, since the average generation of solid household waste per capita is approximately 0.4 ton. The levels of solid-waste recycling are no less important, since our country currently reprocesses less than 40 percent of industrial waste and only 7-10 percent of solid household waste. Meanwhile, the annual increase in solid household waste is becoming one of the major pollutants of the environment. 
The system for evaluating the effectiveness of environmental programs must also take into account parameters of environmental effectiveness, which must help to evaluate in the most objective manner possible the impact of measures taken on the environment, as manifested in an improvement of the composition of water, air, soil, and the environment as a whole, including an increase in a region's assimilative capacity. They may also be parameters showing the downward trend in the amount of pollutant emissions and discharges as a result of using highly efficient waste-treatment facilities, introducing advanced production technologies, and creating no-waste production lines, which can have a significant positive impact on the environment and on the increase in its biodiversity.

This group of parameters is of primary importance, since almost 60 percent of Russia's population currently lives in environmentally polluted territory and more than 33 percent of city dwellers live in cities with a high level of air pollution.

Parameters of social effectiveness should reflect the degree of utility for the population and society as a whole from implementing environmental measures, specifically evaluate what changes occurred in the morbidity rate and the mortality rate of the population living in the unfavorable environmental zone as a result of reducing, for example, hazardous emissions into the environment.

Social and environmental effectiveness may be manifested, for example, in an increase in life expectancy and the preservation and restoration of natural resources, as a result of limiting or eliminating the negative impact of economic and production activities on human health and the environment.

Parameters of economic effectiveness should evaluate the economic effect from implementing environmental measures, such as the amount of economic benefits, both for consumers of government services (legal entities and individuals) and for the government agencies implementing these programs. In particular, the economic effect may be manifested, for example, in an increase in the value of preserved natural resources and a decrease in budget expenditures on health care for the treatment of illnesses caused by environmental problems.

It should be noted here that the implementation of an environmental program that is ineffective for the environment and for society cannot be considered sound even if it is economically beneficial.

The development of a system for evaluating the effectiveness of a government program is not especially difficult, since during this phase it is usually a matter of evaluating the attainment of overall final objectives. For example, in environmental programs aimed at preserving/improving the environment, such a parameter may be a number for air quality, defined by the amount of air per million particles (in \%); in social-block programs aimed at reducing unemployment and poverty, one can use indicators of employment and the share of the population with incomes below the poverty level.

At the same time, the development of a system for evaluating effectiveness at the subprogram level may involve serious difficulties. A whole host of experts point to the problem of choosing parameters for evaluation that correspond to the tasks of the subprogram. The reason for this is that in the context of subprograms, as a rule, there is a greater need for collecting and evaluating data. 
The results of the evaluation may be used to analyze the effectiveness of the actions of a program. This will make it possible to improve the quality of the formulation of similar programs. If a program is designed for several years (which is typical for environmental programs), then an annual evaluation of the results obtained will allow for adjusting the program's actions in subsequent years.

For the actions of environmental programs, there should be a mandatory evaluation of their positive impact on the environment. In addition, the evaluation of their effectiveness requires taking into account the natural and climatic characteristics of each region that is covered by the program.

The evaluation of economic effectiveness should be preceded by an evaluation of environmental and social effectiveness, since the economic benefit from implementation of programs is measured to no less an extent, and even more, by social and environmental benefits and losses. To this end, one should use special methods such as a cost-benefit analysis and a cost-effectiveness analysis, which best fit the evaluation of environmental actions.

Other methods that better suit other types of programs may also be used for the evaluation procedure. The set of evaluation methods should be formed according to the specific nature of the government program.

\section{The program budget from a regional perspective}

The budget-reform process, especially with regard to introducing special-program budgeting in Russia, is continuing to develop. As part of the transition beginning in 2016 to preparing budgets in a program format, regions must do a great amount of work in the immediate future, including work to build the varied current programs (SFPs, various kinds of regional programs) into the new budgeting model.

Budgets have already been produced on the basis of government programs in almost twenty Russian constituent entities, including the city of Moscow; Volgograd, Leningrad, Kaliningrad, Penza, Rostov, Tver, Sverdlovsk, Murmansk, and Omsk regions; Khabarovsk and Primorye territories; the Republic of Chuvashia; and others. In addition, regulations governing the procedure for formulating and implementing government programs have been adopted in almost fifty regions. Substantial progress was achieved in 2013-2014 with regard to producing program budgets in regions, since, as data from the Ministry of Finance of the Russian Federation show that in 2012 the share of program expenditures in a whole host of constituent entities was not more than 5 percent. It can be concluded, therefore, that last year, despite the decrease in budget revenues and the increase in the budget deficit, Russia's regions took vigorous actions to introduce program-budgeting technology.

Russian regions take a variety of approaches to producing a program budget. One of the indications of this variety is the number of government programs. It ranges from 49 (Republic of Dagestan) to 11 (Chukchi Autonomous Region). It is interesting that 16.9 percent of the budget expenditures of the Republic of Dagestan are earmarked for implementing its 49 government programs in 2014, yet the list of government programs of the Republic of Dagestan consists of 53 programs. There are also significant differences in the effective periods of the government programs. Although the most common version is a government program for 
the period up to 2020, there are cases in which programs are adopted for shorter periods (beginning with three or four years).

The number of government programs in various Russian regions is probably determined by the desired degree of detail. In this regard there are attempts to consolidate the "uncombinable" - for example, the Tula Region adopted the government program "The Development of Education and Archiving in the Tula Region." Here is an example of excessive detail: The Republic of Dagestan adopted the government program "The Training of Dagestani Athletes for the XXXI Summer Olympic and XV Summer Paralympic Games in 2016 in Rio de Janeiro, Brazil, the XXII Summer Deaflympic Games in 2013 in Athens, Greece, and the XXIII Summer Deaflympic Games in 2017," with budget appropriations for 2014 totaling 104,617,000 rubles. On a parallel track is another government program, "The Development of Physical Fitness and Sports in the Republic of Dagestan," with budget appropriations for 2014 totaling 94,085,000 rubles. This sort of "breakdown" seems highly debatable, considering the spending amounts that are provided for their implementation.

The experience of transitioning to program budgeting in various constituent entities of the Russian Federation shows that each of them, to a greater or lesser extent, has encountered a whole host of problems that seriously impede organizing the actual process of formulating government programs and approving the budget in a program format. These problems are both of an objective nature, involving problems with legal and methodological support, and of a subjective nature, involving administrative stereotypes in specific regions. In addition, these problems may be divided into external (those directly dependent on federal authorities) and internal (dependent directly on the regional leadership). Despite the substantial quantitative differences in the lists of government programs, however, all of the Russian regions that are developing program instruments tend to have similar problems. The reason for this is that in most cases Russian regions continue, with admirable consistency, to borrow federal experience (which is often not completely refined), thereby transferring to the regional level budget practices that are by no means the best. Nevertheless, some constituent entities of Russia (e.g., the Tver and Volgograd regions and the Republic of Chuvashia) have accumulated fairly positive experience in applying special-program budgeting, which can be used with success by other regions in formulating budgets on the basis of government programs.

\section{The contours of new budgetary reforms}

The next important area in continuing Russian budgetary reforms is a transition to long-term budget planning, which will take place within the framework of budget rules and the strategic planning system, since a law "On Strategic Planning in the Russian Federation" (No. 172-FZ of June 28, 2014) has been adopted. Its main purpose is to create a legal basis development, construction and operation of a comprehensive strategic planning system in the area of Russia's socioeconomic development and national security. The law expands the period of forecasting and planning beyond the framework of the budget cycle (three years) and regulates the adoption and implementation of medium-term (three to six years) and long-term (more than six years) decisions. 
The adoption of this law requires substantial modernization of the budget laws, so in 2014 a new version of the Russian Federation Budget Code was adopted. It was intended to be a more systematized and convenient document that conforms to the new economic and budgetary realities. The principal complaints about the Budget Code have been that it lacks fundamental principles and contains numerous amendments. No one denies that the amendments improve the regulatory instruments, but there are already about a hundred of them, which significantly complicates their use. As a rule, these amendments were a response to some political tasks that came out of the Budget Message of the President of Russia. Therefore, two principles that are to be applied to the new version of the Budget Code are to systematize and codify it.

The adoption of these documents is of great importance, since, due to the specific features of the current system of public administration and budget planning in the Russian Federation, a number of problems arise, including the following:

(1) difficulties in selecting parameters for the productivity of government programs due to their multifaceted nature and structural differences;

(2) disagreements among the participants in the budget process regarding the composition and structure of federal budget expenditures on the implementation of government programs;

(3) specific sectoral features of some government programs that must be taken into account when evaluating the effectiveness of their implementation;

(4) the necessity of improving the system of governmental financial oversight to further ensure the economical and efficient utilization of budget funds;

(5) the selection of tools for evaluating effectiveness, including the determination of parameters for the productivity of government programs.

In addition, as a result of the slowdown in Russia's economic growth, the allocation of budget resources constantly needs to be optimized based on adjustments in socio-economic priorities and the goals of public policy. Moreover, given that government services are provided on a nonmarket basis, it is essential to constantly improve work aimed at increasing the effectiveness of budget expenditures, since attaining a certain level of effectiveness is becoming an important phase on the path to improving the efficient operation of the public administration sector. This process, however, is a long way from being completed. For example, the transition to a full-scale program budget is postponed every year. The procedures for adopting amendments to legislative statutes that would make it possible to do this within the originally planned time frame have been extremely protracted. The Program for Improving the Effectiveness of Budget Expenditures Until 2012, one of the areas of which was to introduce special-program administrative methods, has smoothly changed into another one - "Program for Improving the Administration of Public (Governmental and Municipal) Finance for the Period Until 2018" - most of which repeats the tasks that were not accomplished under the previous one. One of the important areas of this recently adopted document continues to be the modernization of the budget process during the introduction of special-program administrative methods.

There is no doubt, therefore, that work should be continued on refining all of the types of budget programs that are being implemented in Russia, both with re- 
gard to objectives and with regard to the system of parameters for evaluating effectiveness. At the same time, it is essential to fundamentally improve planning procedures. Above all, one should not plan what is basically unattainable: there must be complete conformity between the needs being planned for and existing financial capabilities, since for a whole host of programs there simply are not enough budget appropriations to carry out planned activities. Obviously, such budgetary decisions cannot be regarded as completely responsible.

The next problem is that in regard to the transparency of budget procedures the potential readiness of the government and society has not yet been transformed into actual mechanisms by which agencies will provide full budgetary information and the public will influence on the budget process. The disclosure of budget information, however, will have a beneficial impact on the quality of budgets at all levels. The initiative here must come not only from government entities; the Russian public must also play a role. Without such crisscross initiatives, it seems impossible make full use of all the advantages that a program budget (unquestionably) offers.

So experts and practitioners should focus their attention on introducing approaches into the Russian budget process that are aimed at efficient administration of government programs. What is difficult about this task is that the specific nature of the Russian program-budgeting model prevents the direct borrowing of methods that are successfully used in countries that have transitioned to the program-format budget.

As a result, despite a number of obvious achievements, the budgetary reform process has not been completed. All the more so since, at a time of economic turbulence, one cannot rule out the emergence of serious new challenges based on the exacerbation of domestic and foreign imbalances, which require constant adjustments of budget strategy and budget policy in the Russian Federation.

\section{REFERENCES}

1. Afanasiev, M.P. \& Krivogov, I.V. (eds.) (2006). Modernizatziia gosudarstvennykh finansov [Modernization of state finances]. Moscow: Higher School of Economics.

2. Afanasiev, M.P. \& Shash, N.N. (2013). Instrumentarii otsenki effektivnosti biudzhetnykh programm [Instruments for evaluating the effectiveness of budget programs]. Public Administration Issues, n. 3, pp. 48-69.

3. Afanasiev, M.P. \& Shash, N.N. (2014). Rossiiskie biudzhetnye reformy: ot programm sotsial'no-ekonomicheskogo razvitiia do gosudarstvennykh programm Rossiiskoi Federatsii [Russian budgetary reforms: From programs for social and economic development to state programs of the Russian Federation]. Public Administration Issues, n. 2, pp. 48-64.

4. Afanasiev, M.P., Shash, N.N. \& Belenchuk, A.A. et al. (2012). Programmnyi biudzhet [Program budget]. Edited by M.P. Afanasiev. Moscow: Magistr: INFRA-M. 